\title{
Connecting self-efficacy and views about the nature of science in undergraduate research experiences
}

\author{
Gina M. Quan* and Andrew Elby ${ }^{\dagger}$ \\ Department of Physics University of Maryland, College Park 082 Regents Drive, College Park, \\ Maryland 20742, USA
}

(Received 29 December 2015; revised manuscript received 13 September 2016; published 21 November 2016)

\begin{abstract}
Undergraduate research can support students' more central participation in physics. We analyze markers of two coupled shifts in participation: changes in students' views about the nature of science coupled to shifts in self-efficacy toward physics research. Students in the study worked with faculty and graduate student mentors on research projects while also participating in a seminar where they learned about research and reflected on their experiences. In classroom discussions and in clinical interviews, students described gaining more nuanced views about the nature of science, specifically related to who can participate in research and what participation in research looks like. This shift was coupled to gains in selfefficacy toward their ability to contribute to research; they felt like their contributions as novices mattered. We present two case studies of students who experienced coupled shifts in self-efficacy and views about nature-of-science shifts, and a case study of a student for whom we did not see either shift, to illustrate both the existence of the coupling and the different ways it can play out. After making the case that this coupling occurs, we discuss some potential underlying mechanisms. Finally, we use these results to argue for more nuanced interpretations of self-efficacy measurements.
\end{abstract}

DOI: $10.1103 /$ PhysRevPhysEducRes.12.020140

\section{INTRODUCTION}

Participating in research is an important aspect of becoming a physicist. Undergraduate research can help facilitate students' transition from seeing themselves as physics students to seeing themselves as more central participants in the physics community [1]. Research experiences can also increase students' persistence in science, technology, engineering and mathematics (STEM) [2]. Prior studies about undergraduate research inform a wide set of national recommendations to increase the number of undergraduate students participating in physics research $[2,3]$.

Those studies suggest that undergraduate research benefits students in many ways, including the development of technical skills, content knowledge, and students' identity and beliefs about doing science [4-6]. Undergraduate research experiences also impact career choices, clarifying students' interest in pursuing graduate studies $[4,5]$. These results are consistent across a range of STEM disciplines and different research methods, including student surveys [5-7] and ethnographic investigations $[4,8,9]$. For instance, a qualitative study by Laursen et al.

\footnotetext{
"gquan@umd.edu

elby@umd.edu
}

Published by the American Physical Society under the terms of the Creative Commons Attribution 3.0 License. Further distribution of this work must maintain attribution to the author $(s)$ and the published article's title, journal citation, and DOI. identifies student-described and faculty-described benefits of doing research in successful summer undergraduate research programs $[4,8,9]$. They found that the most frequently expressed benefits include learning to think like a scientist (including knowledge of scientific content and processes) and personal-professional gains, which includes a sense of personal belonging and beliefs about one's ability to do science [4]. Taraban and Logue, using the Undergraduate Research Questionnaire (URQ) [5,10], reached similar conclusions. They found that students improved the most in research mindset, which probes self-concept and selfefficacy, as well as research methods, which probes selfefficacy about doing experimental research. Similarly, Lopatto created a Survey of Undergraduate Research (SURE) and found the highest gains in students' selfreported learning about how the research process works and preparation for future research [6].

However, undergraduate research is not equally productive for all students. The extent to which students benefit depends on the type of research program, the day-to-day work (e.g., "real" work vs scut work), and mentorship quality $[5,11,12]$; mentors who spend more time with the mentee and make themselves more available tend to be associated with more positive identity development and learning gains $[5,9,11,12]$. In summary, previous investigations of undergraduate research experiences have documented

(1) self-efficacy and knowledge about the doing of science as two major areas in which students show positive shifts, and 
(2) coarse-grained factors, such as mentor time commitment and the intellectual richness of students' day-to-day activities, that contribute to these and other positive shifts.

These results motivate research that goes beyond documenting positive shifts in attitudes and understanding associated with undergraduate research; we need to understand in finer-grained detail how these shifts come about, and how they help to constitute students' trajectories in research. In particular, understanding how shifts along one dimension trigger or support a shift in another can help uncover mechanisms that could inform the efforts of research mentors and program leaders to make research experiences even more productive for more students.

In this paper, we illustrate how shifts in undergraduate researchers' views about the nature of science can be coupled to shifts in their self-efficacy about doing physics research. First, using previous literature, we define and situate the aspects of "self-efficacy" and "views about the nature of science" on which we will focus. In previous literature, we see hints of coupling between them. Then, after introducing the undergraduate research program in which our participants were engaged, we present case studies of three students. In each case, we show how shifts in self-efficacy (or lack thereof) were coupled to shifts in views about the nature of science (or lack thereof). Finally, we argue that this analysis can inform efforts to improve undergraduate research experiences and also illustrates how shifts in self-efficacy as measured by surveys may be conflated with shifts in views about the nature of science.

\section{SELF-EFFICACY AND VIEWS ABOUT NATURE OF SCIENCE: WHY THEY MATTER}

The coupling between self-efficacy and views about the nature of science is worth studying partly because, taken separately, the two constructs are consequential in their own right. Undergraduate research experiences can also lead to positive shifts in both, as discussed above. In this section, we further argue for the importance of these two constructs, clarify what we mean by them, and pinpoint which aspects of the constructs we will target in our analysis.

\section{A. Self-efficacy}

Self-efficacy, belief in one's ability, is tied to student success in physics [13], persistence in school [14,15], and interest [15]. However, different studies have operationalized this construct in different ways. Bandura initially defined self-efficacy as beliefs in one's ability to complete a specific task, and this construct was embedded in a larger social cognitive theory of epistemic agency and learning [16]. Research grounded in these ideas often consists of large- $N$ studies confirming Bandura's hypothesized contributors to self-efficacy: mastery experiences (succeeding at task), vicarious experiences (e.g., seeing someone "like you" succeed at a task), verbal persuasion (receiving encouragement or discouragement from others), and physiological factors (interpreting physical and emotional responses such as anxiousness) [16,17].

As adapted to studies of mathematics and science learning, self-efficacy is usually broader than belief in ability to complete a specific task. For example, the Sources of Self-Efficacy in Science Courses-Physics (SOSESC-P) [18] survey solicits students' level of (dis)agreement with statements such as

"I am capable of receiving good grades on my assignments in this class."

"Listening to the instructor and other students in question-and-answer sessions makes me think that I cannot understand physics."

"I don't usually worry about my ability to solve physics problems." [19]

These items probe students' self-efficacy for succeeding in their physics class. By contrast, other researchers have created subscales targeting self-efficacy about research. For instance, one subscale on the URQ [10], Research Methods, specifically probes self-efficacy for research, with these six items:

"I can design experiments."

"I troubleshoot experiments."

"I understand how to report experimental results."

"Generating hypotheses is something I can do."

"Data analysis is something I can do."

"Carrying out experiments is something I can do."

Note that the first five items align with Bandura's original notion of self-efficacy as associated with a specific task. But in reporting results, many physics education researchers often focus on the subscale as whole, interpreting it as self-efficacy about research in general. What emerged in our data was a broader sense of confidence than the kind probed by individual items in the URQ Research Methods subscale; students came to believe that they could make meaningful contributions to authentic research, without necessarily specifying specific research tasks. In this paper, we label student statements related to confidence and ability in research as self-efficacy for research, or just self-efficacy for short, while acknowledging that we are using this term more broadly than some.

\section{B. Views about the nature of science (NOS)}

Many science educators, including those who study undergraduate research experiences, consider sophisticated views about the nature of science to be an instructional goal in its own right $[8,20-22]$. In this section, we spell out 
which aspects of students' views about the nature of science (NOS) are explored below, relating those aspects to previous literature on students' NOS views. To set up this discussion, we first briefly review how views about the nature of science have usually been operationalized and studied in educational contexts.

NOS views, as studied in most of the science education literature, are beliefs about "the epistemology of science, science as a way of knowing, or the values and beliefs inherent to scientific knowledge and its development," e.g., beliefs about the nature and generation of scientific knowledge [20]. Lederman et al. [21] characterize these views as belonging to several interrelated dimensions: "scientific knowledge is (i) tentative; (ii) empirical; (iii) theory-laden; (iv) partly the product of human inference, imagination, and creativity; and (v) socially and culturally embedded."

Lederman et al. [21] acknowledge that their NOS instruments, the Views about Nature of Science (VNOS) forms A through $\mathrm{C}$, emphasize aspects of NOS which are most accessible to K-12 students. By contrast, our data speak most directly to students' views about how science is done-how scientific knowledge is constructed-in collaborative academic laboratories. This is a slice of the nature of science to which K-12 students have little access and which can vary by (sub)discipline, research group, and research goals for a particular project [23-25]. So, it makes sense that VNOS and similar protocols or surveys do not "get at" the aspects of NOS upon which we focus, as described below.

Although our study did not specifically target any particular aspects of students' views about the NOS, two aspects emerged as central in students' descriptions of their experiences:

(i) The distributed nature of scientific work-students' views about the extent to which multiple workers, with different levels of expertise, meaningfully contribute to the generation of scientific knowledge.

(ii) The interplay of theory, simulation, and empirical work-students' views about the extent to which theoretical thinking, simulations or modeling, and empirical data collection and analysis interact in complex ways.

Note that (i) and (ii) live at the intersection of the epistemology of science, addressing aspects of how scientific knowledge is socially constructed [26,27], and the sociology of study as studied by anthropologists, historians, and sociologists (sometimes under the banner "science studies") seeking to understand the culture and interactions of scientists [24,25,28-30]. Also, (ii) refers not to students' understanding that empirical data is central to science (Lederman et al.'s second dimension of NOS), but to students' understandings of how empirical, simulation or modeling, and theoretical work interact in nuanced, diverse ways in different scientific investigations.

\section{Hints of coupling between NOS views and self-efficacy}

Previous work on undergraduate research experiences has not focused on the relationship between shifts in selfefficacy and shifts in views about NOS. However, this literature provides glimmers of evidence that such a coupling might exist. Although previous literature categorizes and usually presents student outcomes in ways that separate self-efficacy and views about NOS, we found one interview response from a prior study that hints at a connection between the two. Hunter et al. present the following student quotation as an illustration of "gains in understanding of the character of research work and the realization that doing research requires perseverance," e.g., a shift in views about the "nature of research work" [8] (p. 49):

It's helped me to deal with failure in the laboratory. And it's not your fault. It's not anything you could have done. It's just the protocols that worked perfectly for so-andso don't work for you because of reasons you didn't even think about and nobody thought about. It's helped me to be a better problem-solver, I think, to look at this and say, Okay, we'll pinpoint what's going wrong. We'll see what other people have done. We'll see why ours is different and how we can change things so that it will work.

We agree with Hunter et al. that the student demonstrates an increased understanding of scientific research, the idea that failure is part of the process, and that reflecting on the reasons for the failure is productive. What Hunter et al. do not comment upon, however, are the signs of increased selfefficacy for doing research: the student thinks her research experience has "helped me become a better problem solver," capable of trying to "pinpoint what's going wrong" and "change things so that it will work." Furthermore, we see glimmers of evidence that this positive shift in selfefficacy is coupled to the shift in the NOS view that failure is part of the scientific process. In the quote, the student's first mention of increased self-efficacy, "It's helped me to deal with failure in the laboratory," is immediately followed by comments about the nature of science, that "it's not your fault. It's not anything you could have done." This discursive flow suggests that these are connected; realizing that science inevitably involves failure helps the student see failure as not her fault and, hence, as something she can become better at addressing.

Our point here is not to criticize Hunter et al.'s analysis, which focused on identifying and illustrating benefits of undergraduate research experiences, not on explicating interactions between those benefits. This likely explains why the above quote is the only example from Hunter et al.'s analysis that addresses both views about NOS and self-efficacy; and as a result, we cannot speak to how 
representative it is of the experiences of that population of students. Rather, our point is to show that glimmers of a connection between shifts in self-efficacy and shifts in NOS views are already present in previous work on undergraduate research experiences, but have not been analyzed. In this paper, we highlight how shifts in self-efficacy and in NOS views may interact, motivating future work on this particular connection and on links between other potential outcomes of undergraduate research experiences.

\section{METHODS AND CONTEXT}

\section{A. Classroom and laboratory context}

Physics 299B: The Physics Toolbox, at the University of Maryland, College Park, was co-developed and co-taught in 2013 and 2014 by the first author and another instructor. 299B introduces undergraduate freshmen and first-year transfer students to authentic physics research. All firstyear physics majors who were not currently engaged in research were encouraged to enroll during advising. In 2013, the course enrolled twelve students in 2013 and fifteen students in 2014. (The physics department typically has about 50-60 first-year freshmen and transfer students per year.) Instructors recruited mentors (faculty, postdocs, and advanced graduate students) whom they felt would create meaningful learning opportunities in their research labs. Mentors proposed projects of reasonable complexity for a first-year undergraduate to complete in one semester. Students were matched with mentors based on topical interest. For 3-5 hours per week over 15 weeks, students worked with their mentors on research projects.

Research projects spanned experimental and theoretical areas of physics and astronomy. Two students in this paper, Frederick and Savannah, worked in separate experimental condensed matter labs, and both were supervised mainly by graduate students. Wyatt worked with research scientists on a project studying black holes. Each mentor was given a set of mentor guidelines which outlined the expectations for time commitment, made recommendations for bounding an appropriate-sized project within the time constraints, and listed topics covered in the 299B course. The mentor guidelines also emphasized that course goals included students feeling a "sense of accomplishment" and that they contributed to "real research." Developing sophisticated views about the nature of science and developing confidence in research abilities were not mentioned in any communications with mentors. Without additional data such as research observations or mentor interviews, we cannot know whether students had explicit discussions about NOS or self-efficacy in their research labs.

We find it likely that differences in mentorship (e.g., graduate student or not, mentor personality, etc.) significantly impacted students' experiences. However, our purpose in this paper is not to understand how individual mentors uniquely influenced student experiences. Rather our goal is to show that NOS views and self-efficacy are plausibly linked, a coupling we observed for multiple students in multiple labs.

In addition to working on research projects, students met for 2 hours per week in the 299B seminar. Two central goals guided design of the course: (i) developing a supportive community that shares the ups and downs of doing research, and (ii) giving students opportunities to reflect on and be proud of their work. As a result, much of the seminar consisted of small-group and whole-class reflection on the research activities. Discussion prompts occasionally broadly touched on NOS views, e.g. "So what do you guys think you learned about the process of doing research in your internships?" but did not explicitly probe for NOS views about the distributed nature of scientific work or the interplay of theory, simulation, and empirical work. The seminar also covered research skills applicable to all the research projects, such as reading literature and keeping a lab notebook. The course culminated in a poster session whose attendees included mentors, and faculty and undergraduates not involved in the seminar.

\section{B. Analytical flow}

\section{Data collection}

We initially collected data to understand how students' identities developed during their research experiences, and to identify productive aspects of the course. In Spring 2014, we videotaped the 299B sessions, administered student surveys, and collected instructor field notes and student coursework. Throughout Summer and Fall 2014, we invited all fifteen students from the 2014 cohort to be interviewed. Nine students participated. In the interviews, we asked students to describe their attitudes toward research before and after the research experience, what they got out of doing research, and how they saw research as fitting (or not) into their physics course sequence. Because the self-efficacy or views about NOS connection emerged during our analysis, we did not explicitly probe for either construct in interviews or surveys. Interviews were semistructured; the protocol loosely directed the conversation and the interviewer pursued in more detail ideas and experiences that were most salient to students [31].

Interviews were conducted by the first author, who coinstructed the course. While the power relations inherent in the instructor-student relationship can amplify the power dynamics present in all interviews, we mitigated these in two ways. First, the other co-instructor, not a member of the research team, did all the grading. Second, we conducted all interviews after final grades were assigned. Despite these safeguards, we were concerned, as in any interview-based study, that students would consciously or unconsciously say what they thought the interviewer wanted to hear. However, in these interviews and through other channels such as course evaluations, students willingly critiqued many aspects of their course and lab experiences. We take 
this as evidence that students did not feel pressured to say (only) positive things about their research experiences. Furthermore, the relationship between students and the interviewer also afforded an ongoing rapport and helped us better understand and interpret participants' language and understand specific events and contexts to which they referred [32].

\section{Analysis}

The first author transcribed every interview and some classroom episodes. In analyzing a few early transcripts, we noticed a connection between shifts in students' NOS views and self-efficacy. To see if other researchers would notice and interpret this connection in similar or different ways, we engaged our broader research group in a video analysis session, discussing multiple interpretations in an attempt to find the one(s) best supported by data [33]. Looking at literature, we also found that the connection between selfefficacy and NOS views had not been previously explored in the context of research experiences, but that data in another study hinted at this connection, as discussed in Sec. II C.

Identifying emergent themes can be theoretically fruitful as it helps illuminate new causal mechanisms and connections that can be verified and fleshed out in later research. For example, Schoenfeld describes how many of his contributions, including his studies of metacognition, stem from observations of unanticipated phenomena and unexpected results [34]. As another example, Engle and Conant's framework for Productive Disciplinary Engagement emerged from a conversation which unexpectedly "took off," leading them to compile and refine a set of guiding principles to support such Productive Disciplinary Engagement [35]. As Engle, Conant, and Greeno describe, researchers decided to pursue this "taking off" for its potential in supporting disciplinary engagement [36].

In our research, we identified a connection between shifts in NOS views and self-efficacy as one emergent theme to explore further in this study, a theme that emerged primarily from analysis of one classroom episode and one student interview. We then systematically focused on selfefficacy and views about NOS in analyzing interviews, classroom discussions, and surveys involving the other students in this data set. As in Engle, Conant, and Greeno's description of theoretical refinement based on an emergent theme, we applied an analytical approach of Progressive Refinement of Hypothesis, an iterative cycle of developing a research claim, testing the claim against a larger set of data (more segments from the previously analyzed interviews, plus previously unanalyzed interviews), and refining the research claim in analytic memos [36]. We repeated this process in analyzing the other interviews and classroom episodes in order to strengthen our theoretical claims, as in prior studies which look for theoretical generalizability of claims [36,37]. Specifically, we attended to counterexamples in which there were no NOS views and self-efficacy connection and when those connections looked different from what we observed with our original analyses [37].

Markers for self-efficacy were statements related to a student's ability to do research and statements related to their confidence. For example, a student saying that she would feel more confident getting started in a new research project indicates high self-efficacy because the student explicitly expresses confidence in her abilities. A student saying that he would not be able to learn advanced math for a research project would be a marker of (low) self-efficacy, because it speaks to his belief in his ability. In our interviews, we identified shifts in self-efficacy from students' explicit assertions of such shifts, e.g., a student saying that they are now more confident or less nervous than before.

Our approach toward identifying NOS views was similar to Hunter et al.'s [8], in which students were prompted in interviews to broadly reflect on the nature and value of their undergraduate research experiences [38]. They then characterized students' reported outcomes into broad categories which emerged, including "thinking and working like a scientist" which includes the subcategories "understanding of the nature of scientific knowledge" and "increased knowledge of and understanding of scientific research and work." We similarly looked for views about the nature of scientific knowledge by tagging students' descriptions of research which were explicitly tied to their conceptions of scientific knowledge and how it is generated. For example, statements about who can participate in science are markers of students' views of science as a social enterprise, and more specifically, about the distributed nature of scientific work. However, because views about science as a social enterprise and the distributed nature of scientific work involve students' epistemological views and also views about their interactions with others, we need to clarify what counts as this dimension of NOS in our analysis. As in most current work on students' and teachers' NOS views [22], we look for evidence that a student's statement about the social or collaborative nature of science relates to the way that scientific knowledge is generated. For instance, if a student comments that novices in the lab are invited to join the research group for lunch and this makes the student feel like part of the group, we do not flag this as views about NOS. By contrast, if the student says that she feels like part of the group because her lab work as a novice contributes to the group's research, we flag this as the NOS view that novices can contribute to scientific knowledge generation.

Seven of the nine students interviewed in 2014 described shifts in self-efficacy and NOS views. However, in our analytical flow, the role of most of these students' interviews was to help us confirm and refine our sense of what counted as evidence of self-reported shifts in self-efficacy and in views about NOS, which we then used to refine our 
analyses of the students targeted earlier in the process. These later interview analyses also served as confirmation that we were not just "seeing things" in our earlier analyses. Furthermore, in this small- $N$ study, our goal is to provide an existence proof and illustrations of the coupling between shifts in self-efficacy and NOS views, not to make claims about prevalence. For these reasons, this paper focuses on two students who described self-efficacy shifts connected to shifts in NOS views, and as a contrasting case, a student who showed no evidence of shifting along either dimension.

For brevity, the data we present for each student comes from either the interview or a classroom discussion. Because written survey responses only occasionally mentioned NOS views or self-efficacy, we did not include them in this paper. In all cases, the student's statements in other data streams are consistent with the views we are attributing. So, the quotes in this paper are chosen for articulateness or clarity of the students' views. Nonetheless, we cannot make claims about the stability of students' views because NOS views and self-efficacy are sensitive to the interview and classroom contexts [40]. Still, we take students' narratives at face value as representing salient aspects of their experiences in the context the data were taken.

\section{Choice of case studies}

Crucially, among the students who exhibited shifts in NOS views and self-efficacy, the finer-grained details of their shifts differed. For this paper, we chose two students whose experiences illustrate both the variations in the details and also the commonalities among the shifts. "Wyatt" found that cosmology research did not require advanced mathematics and that there was a place for novices to participate. This contributed to his shift toward thinking he could make worthwhile research contributions. By contrast, Frederick came to see lack of knowledge- a sense that "nobody knows what they're doing"-as a normal part of research. This normalization of uncertainty, we argue, contributed to his increased sense that he could contribute to research. For both Wyatt and Frederick, we argue that these shifts in NOS views and in self-efficacy are coupled rather than merely contemporaneous.

After presenting our analysis of Wyatt and Frederick, we present Savannah, a student who gained confidence in her internship but who did not experience a self-efficacy shift about doing research or show evidence of changing her NOS views. We use Savannah as a contrasting case to Wyatt and Frederick. We note, however, that her case supports our argument that shifts in self-efficacy and NOS views are coupled, because a single mechanism contributed to her lack of shift in NOS views and self-efficacy about her research abilities.

For students not shown here who experienced selfefficacy and NOS shifts, the details of these shifts also differed, but in ways that suggested coupling. For example, Dakota learned that research is not just done by "the best and the brightest," which coupled to her self-efficacy in research. In other cases, self-efficacy and NOS views were entangled with other constructs such as interest and identity, constructs that were more salient to the student than the foci of this analysis, but that also mediated linkages between NOS views and self-efficacy shifts.

In Sec. V, we explore alternative possible causal relationships between self-efficacy, NOS views, and other factors. Given the variation across research experiences, we expect different sets of mechanisms to be initiating and/or supporting the coupling of self-efficacy and NOS views in each cases. Indeed, we find it interesting that the same phenomenon-that self-efficacy and NOS views are connected - could be present in cases with (likely) different underlying mechanisms.

\section{RESULTS}

\section{A. Wyatt \\ 1. Shifts in Wyatt's nature of science views}

Wyatt's NOS views shift with respect to the distributed nature of scientific work dimension and the interplay of theory, simulation, and empirical work dimension (specifically with respect to cosmology). At multiple points in the interview, he describes research as a hierarchy with room for novices (such as himself). He also describes cosmology as a field where data are collected and analyzed, contrary to his previous impression. He expressed these views multiple times. For instance, discussing his evolving feelings towards his research, Wyatt says,

Wyatt: You're always kinda intimidated at first when you get into research. Cause you're like, postdocs and you don't wanna waste their time, and they work on big things and it's like oh, I'm just a freshman.

Interviewer: So do you feel like you're less intimidated by your research now?

Wyatt: Ah yeah definitely. Cause I don't know, there's always a place for anyone with a certain, skill level... the experts are always gonna be at the top. And wherever they need you, if they decide to choose you at all, that's probably where you're gonna have the best fit.

Interviewer: Mm, So do you feel like you've like, moved up in your fit?

Wyatt: Yeah, a little bit actually. I mean, not just being a sophomore in college as opposed to a freshman, but like having the experience, getting things done, presenting things. I feel a little bit more proficient in research.

Wyatt describes initially having a sense that research is hierarchical, with those at the "top" having knowledge and experience. He contrasts his status as just a freshman to postdocs, suggesting that experience and coursework are 
necessary to do research. This is consistent with a later quote, "I thought [research] was something like reserved to upperclassmen, where you actually knew your stuff." Wyatt initially saw research as being done by those with strong background gained partly from course work.

Wyatt's view of science as hierarchical did not show evidence of shifting. What changed was his sense that there is room at the bottom for novices to make meaningful contributions: "There's always a place for anyone with a certain skill level." This hierarchy also supports upward movement as novices gain experience. Indeed, Wyatt has a sense that he's already moved to a higher position, having gained more experience in research and in college.

Contributing to Wyatt's swing toward thinking that "there's always a place" in research even for novices is a shift in his views about the nature of cosmology research in particular. He describes his first impression of cosmology research as "a mess of math that I am nowhere near prepared for." However, he found that it involved more concrete activities such as "churning data" and "computing data." This is consistent with a shift along the nature of science dimension the interplay of theory, simulation, and empirical work; he now sees cosmology as partly empirical, not just mathematical:

Wyatt: [At first] I was like, man that's serious cosmology. That's probably a mess of math that I am nowhere near prepared for. But I like astronomy so much so I was like "man let me just go for it." And then what I realized it's not so much like, raw theory. They actually do have telescopes, hardware that take all these measurements, and you're just computing all that data. I imagined cosmology being a whole lot more theory. We churn out that data to have something readable, something understandable. And that actually surprised me and changed my view of cosmology.

Wyatt found that some aspects of cosmology research are less math intensive and theoretical than he predicted, which (we now argue) is connected to a sense that he can understand and participate in it.

\section{Shifts in Wyatt's self-efficacy}

Wyatt reports gaining confidence that he is able to contribute to authentic research. His first impression was that research is "intimidating." He positioned himself below his mentors - they work on big things I'm just a freshmangiving a sense that he feels small compared to them. Through participating in research, however, he comes to see a place for freshmen like him to make authentic contributions. By the end of the research experience, Wyatt describes himself as "more proficient in research," suggesting an increased sense of competence.

Wyatt's intimidation in part stemmed from worries about being underprepared for advanced mathematics.
He described his actual project's lack of advanced mathematics as important for his participation: "It was less computational than I thought it would be, which was a godsend because my math isn't the strongest." His research experience did not shift his self-efficacy with respect to math, however; Wyatt reiterates his lack of confidence in his math skills throughout the interview. Nonetheless, Wyatt gained confidence in being able to understand research. He describes learning that the project is "concrete... we churn out that data to have something readable, something understandable," suggesting that it is understandable to him. His use of "we" suggests that he sees himself as an active, legitimate member of the research team.

\section{Coupling between the shifts in self-efficacy and NOS views}

Wyatt's shift in NOS views about the distributed nature of scientific work-specifically, his sense that novices can contribute to authentic scientific research in cosmology-connects to his sense that he can contribute to authentic research, i.e., a shift in self-efficacy. He says that learning that there is "a place for anyone with a certain skill level" led him to see his freshman status as less of a barrier to participation. The hierarchical nature of his relationship to his mentors, instead of making him feel outside the research team, was a source of confidence for him: "they'll tell you how to correct it you still have the reassurance, if this is wrong, they'll probably spot it." This statement reflects Wyatt's sense of reassurance and protection in his mentors' expertise and how interactions with his mentors reinforced the hierarchical nature of their relationship.

Wyatt's initial belief that his research would be math intensive connects to his lack of confidence going in. He describes his math ability as low, and his initial view of cosmology as being theoretical made him feel unprepared. He describes a shift in NOS views along the interplay of theory, simulation, and empirical work dimension for cosmology, which connected to a shift in his sense that he can succeed in it; that his research was data driven and not mathematically challenging meant that his math ability was less of a concern.

A simplified model of the complex coupling between Wyatt's shifts in self-efficacy and NOS views would be that Wyatt gains self-efficacy for research because he comes to see cosmology research as an enterprise to which novices can contribute. This stems from seeing scientific research as "having a place" for novices and because he comes to see cosmology as including empirical work accessible to novices lacking advanced math skills. While this interpretation aligns with Wyatt's statement, we acknowledge that the relationship between Wyatt's self-efficacy and NOS views is likely more complicated. We explore other plausible connections between self-efficacy and NOS views in Sec. V. 


\section{B. Frederick}

Now we turn to a student who experienced shifts in selfefficacy and in NOS views differently from Wyatt, but whose shifts are nonetheless coupled. We use data from a whole-class discussion at the end of the semester where we asked students to reflect on their experiences in research. Frederick describes coming to see scientific research as a less prescribed process than he initially thought, and as an enterprise where "nobody knows what they're doing," which helps him become less nervous about his lack of expertise.

\section{Shifts in Frederick's self-efficacy}

In the following quote, Frederick is responding to a student in class who described feeling more like a scientist through doing research. Frederick describes a shift from "kinda nervous" to "no nervousness."

I'd say that no matter what research opportunity I walked into at this point, I wouldn't be nervous. You know that first time you walk into a research opportunity, you're kinda nervous, you don't know how it's gonna be, you don't know how everything's gonna go down. And I feel like after this experience, I could walk into any research opportunity and, adapt... I feel like I could walk in there with no nervousness now and own it.

Frederick describes gaining confidence in his ability to "adapt" to a new research situation. He describes nervousness upon starting his first research experience, which for him stemmed from not knowing what was going to happen or "how everything's gonna go down." In contrast, he says he is now able to start a new project with confidence, which he describes as "owning it." His recounting of his trajectory in research goes from nervousness, to adapting, to confidence and owning it, which we take as evidence of a self-efficacy shift.

\section{Shifts in Frederick's nature of science views}

In the same class discussion, instructors asked students what they felt like they learned about the process of doing science. Frederick described shifting his views about the distributed nature of scientific work by learning that one can participate in science without knowing exactly what they're doing. Frederick described learning about the uncertainty and flexibility in science:

Nobody knows what they're doing. Seriously. How many people were like "oh, I know exactly where I'm trying to get to and we're gonna figure this out?" Everybody's just kinda ad-libbing it with a general idea of where they want to go. If they get there awesome, if they get somewhere else that's awesome too. Hopefully you just get somewhere away from your starting point.
Though Frederick says nobody knows what they're doing, his statement is more nuanced than suggesting that researchers are totally lost. He highlights how in science, researchers often must improvise and be flexible, which contrasts a common perception that researchers know "exactly where I'm trying to get to." Frederick's statement connects to the distributed nature of scientific work by suggesting that there is a place for novices in science because they can contribute without knowing exactly what they're doing - and indeed, one of the characteristics defining and unifying the lab team is that no one has all the answers, not even the most expert researchers.

\section{Coupling between the shifts in self-efficacy and NOS views}

In this section, we describe a plausible connection between Frederick's growth in self-efficacy and shifts in his views about the nature of science. After some further class discussion, he elaborates on not feeling nervous anymore and suggests that not knowing what one is doing is okay in research.

I should probably elaborate. What I meant, it's a process. Nervous about the process. I walked into something where I had no idea what I was doing, Logan [my partner] had no idea what he was doing, [my mentor] had no idea what he was doing. That was our mentor and he was like, I don't know where this is gonna go. The process of learning and understanding our topic so quickly gave me a lot of confidence that I could walk into any of them, and pick it up like that, the process would be a lot simpler, I wouldn't be nervous about it.

One explicitly-stated source of Frederick's self-efficacy is picking up his research quickly, which is what Bandura would call a mastery experience. We argue that another factor in Frederick's increase in self-efficacy is that his mentor "didn't know what they were doing." Specifically, because his mentor had "no idea what he was doing," Frederick believed that researchers who do not know what they are doing can participate in research.

We acknowledge that the connection between selfefficacy and NOS views is less watertight in Frederick's data than in Wyatt's. Unlike Wyatt, Frederick does not explicitly state this causal link in his description. However, his discursive flow from discussing nervousness to emphasizing how "nobody knows what they're doing" suggests that his shift in NOS views contributes to his shift in selfefficacy.

\section{Savannah}

Finally, we briefly present a contrasting case in which a student does not gain self-efficacy in doing research or show evidence of developing more sophisticated views about the nature of science. Savannah described learning 
that it is okay be a novice, but not that novices can make authentic contributions to research. We argue that a single factor helps to explain why neither her self-efficacy for doing research nor her views about NOS shifted; those nonshifts were coupled in the sense that they shared a common cause.

\section{Lack of shift in self-efficacy for research}

In a class discussion at the end of the semester, Savannah described undergraduate research as a "learning experience." This discussion occurred as she was wrapping up her research in a condensed matter lab, and she had been offered summer research in a different lab.

I was really nervous about, like, I don't know what any of these things are, I don't have a lot of physics background, and doing the research I did in the lab, I realized that it's okay that I don't have all the background. It's a learning process no matter what you go into. And so going into the next thing I'm doing this summer, I've really accepted that I'm probably not going to be doing a lot of research, a lot of it's going to be a learning experience.

While Savannah, like Wyatt, describes feeling nervous for her lack of background and realizing that it is okay to be a novice in a research lab, we don't see a shift in self-efficacy toward doing research. Instead, Savannah describes her participation as a learning process, which she sees as separate from real research. She takes this learning process as given and lack of authentic research as given, "no matter what you go into."

In an interview toward the end of summer, she reiterated similar initial concerns as Wyatt and Frederick about not being able to make a research contribution. She shifts to no longer having this concern, not because she comes to see herself as contributing to research but because she reframes her lab internship as a learning experience.

I always thought uh, that it would, it felt overwhelming but I think the 299B experience helped me understand that whenever you go into a new research experiment or research group you're always going to start off reading and getting caught up with what's going on. And so it's okay to come in not knowing because they're going to make sure that you're gonna learn something and so it was nice, and so my overwhelmed feelings were kind of compressed down and lowered because I knew that coming in I'm not going to know a lot. These people have finished the undergraduate physics courses and are at a higher level and so really, the summer, I took it as a learning experience and not that I have to be just as good.

Like Frederick, Savannah describes initial feelings of stress; and like Wyatt, she contrasts herself to those who have reached a "higher level" from course work.
And similar to both Frederick and Wyatt, she describes how her "overwhelmed feelings" were "compressed down and lowered." Finally, like Frederick, Savannah attributes this affective shift in part to the realization that "it's okay to come in not knowing." But unlike Frederick and Wyatt, Savannah's affective shift is not associated with increased self-efficacy for research. Savannah gains comfort from reframing her activity as not research, but rather, "as a learning experience."

\section{Lack of shift in views about the nature of science}

What are her views about the distributed nature of scientific work? Though less explicitly than Wyatt or Frederick, Savannah also initially stated that novices cannot contribute to authentic research until gaining a certain level of understanding. That's why "whenever you go into a new research experiment or research group you're always going to start off reading and getting caught up with what's going on," a process she experienced as taking the whole semester during 299B. In her summer interview a few months later, she had a similar sense that one cannot contribute to research without first developing background understanding: "I've really accepted that I'm probably not going to be doing a lot of research, a lot of it's going to be a learning experience." We observed consistency over time in Savannah's view that authentic research is done by those with appreciable background understanding, and not a shift in views about who can do research.

\section{Coupling between the lack of shifts in NOS views and self-efficacy for research}

We see a connection between Savannah's lack of a shift in views about NOS and her lack of a shift in self-efficacy toward research. Her framing of her day-today activity as learning rather than research mediated (i) her consistent views of how a certain level of understanding is necessary to do authentic research and (ii) her lack of confidence in making an authentic research contribution. So, those two nonshifts are indirectly coupled in the sense that they are both mediated, in part, by the same factor.

\section{DISCUSSION}

Previous research on undergraduate research experiences has documented positive shifts in students' self-efficacy for research and in their views about the nature of science. In this paper, we gave evidence that these constructs can interact. Wyatt and Frederick illustrate how different shifts in NOS views and shifts in self-efficacy can fit into this general pattern. For example, Wyatt's view of research as epistemically hierarchical persisted throughout his experience, with postdocs and professors higher up the chain than novices, whereas Frederick foregrounded the epistemic commonality between himself and his mentor ("nobody knows what they're doing"). Wyatt found comfort and 
confidence in having people with greater expertise to trust for guidance, whereas Frederick found comfort and confidence in his mentor's lack of complete knowledge, which put him and his mentor in the same boat.

For two reasons, we also presented the contrasting case of Savannah, who described having a positive, productive learning experience in research, but who did not gain self-efficacy toward doing research or shift her NOS views about the distributed nature of scientific work. First, the case illustrates what a lack of shifts in selfefficacy and in NOS views looks like. Second, Savannah supports our claim that self-efficacy may be coupled to views about NOS. The mere co-occurrence of these nonshifts is not evidence of coupling between them. We claim that there is an indirect coupling between these nonshifts because we have identified a factor, her framing of her experience as learning rather than research, that drives both nonshifts.

We emphasize that though we consider Savannah to be a "negative" case of shifts in self-efficacy and NOS views, we (and she) still consider her research experience to be positive. Furthermore, her framing of her lab activity eventually changed; in a follow-up interview after two years working in one lab, she saw herself as now making real research contributions.

Did gender dynamics contribute to differences between Savannah's experiences and those of Wyatt and Frederick? We do not know. Because our analysis started with identifying themes salient to the students in their interviews, and gender was not discussed in our interview or classroom interaction data, we chose not to focus on gender in this analysis. Yet, gender dynamics are always present in interactions, and students might not have brought up gender during the interviews for various reasons. So, although this paper focused narrowly on connections between selfefficacy and NOS views, we see the unfolding of gender dynamics in research lab interactions as a fruitful area of future research.

In this paper, for Wyatt and Frederick, we argued for a tentative directional link between self-efficacy and NOS views: shifts in seeing research as a place where novices can participate led students to see themselves as able to make a meaningful research contribution. Of course, the shifts in self-efficacy and NOS views and the linkages between those shifts are undoubtedly more complex than this single directional link; self-efficacy shifts can also support changes in NOS views (e.g., by helping students dive into research deeply enough to gain insights about how research works), and both of these constructs interact with other components of students' experiences (e.g., being positioned as "real" lab members by mentors). Indeed, the case of Savannah illustrates how lack of shifts in selfefficacy and views about NOS can both depend on another phenomenon, namely, how the student (re)frames their lab activity. Figure 1 models the complex system of NOS,

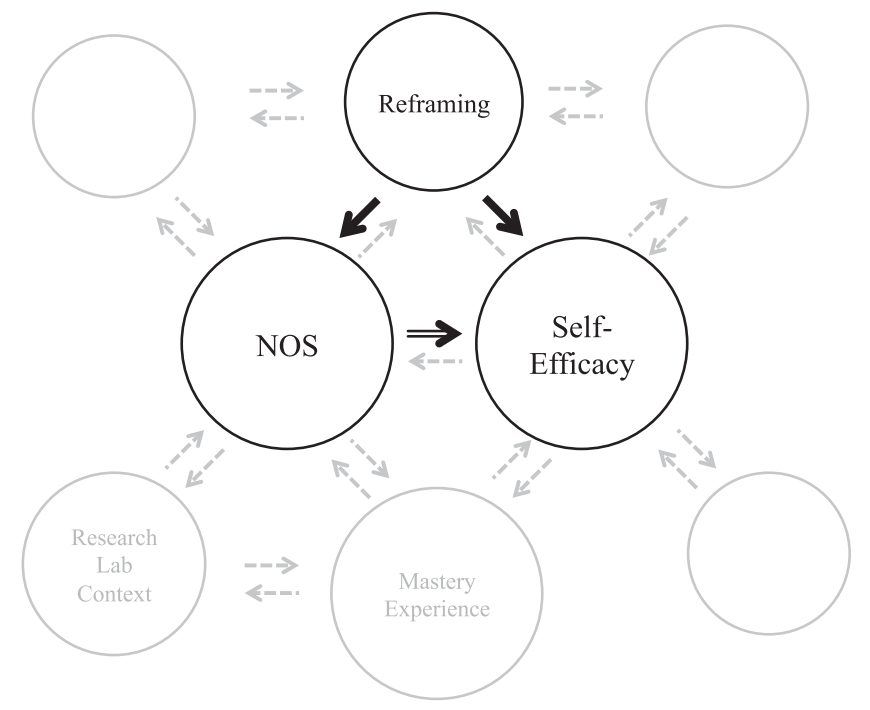

FIG. 1. Diagram representing evidence for the supporting causal connections between NOS views and self-efficacy for Frederick and Wyatt (black double lines) and inhibitory causal connections for Savannah (black solid lines). The diagram also represents connections that may be present but are not supported by data (gray).

self-efficacy, reframing, and other elements. The black parts of the figure represent the evidence we have presented in the paper. The gray parts model connections that may also be present, though we lack data to make specific claims about them.

Similar to how Savannah's reframing contributed to a lack of shift in self-efficacy and NOS views, other constructs might simultaneously influence both self-efficacy and NOS views. Indeed, social cognitive theory has documented several sources of self-efficacy which we suggest might simultaneously fuel a shift in NOS views [16]. For example, being assigned to and succeeding in experimental work pertinent to cosmology $-a$ mastery experience contributing to increased self-efficacy-might also have led Wyatt to see the importance of data collection and analysis in his lab, shifting his NOS views about the interplay of theory, simulation, and empirical work in cosmology research. More speculatively, if Wyatt's mentors gave him encouragement that he was making a significant contribution (verbal persuasion, likely contributing to self-efficacy), that could also have led Wyatt to believe that research has a place for novices. In this paper, we choose to foreground the model in which Wyatt's shift in NOS views supports his self-efficacy shift, because Wyatt attributed his lack of nervousness to his NOS shift in his interview.

We also expect variation in this web of causal connections due to students' experiences in different research groups and in other contexts. For instance, Savannah's mentors could have provided more or less explicit 
messaging about how she was in a "learning" phase rather than doing real research. Wyatt's sense that novices like him had a place in lab could have stemmed from his mentors authoritatively saying so, and/or treating him like a lab team member. Or, these ideas could have emerged in discussions with other classmates based on their own experiences. We would need additional data, such as interviews with mentors and observations of students engaging in research, in order to understand these mechanisms more fully. As possible next steps, a larger quantitative study would shed light on the extent to which one shift can predict the other. Person-centered ethnographic research [41] on undergraduate researchersconducting ongoing observations in lab in addition to interviews-could shed light on the underlying mechanisms of change.

Our goal in this paper is not to argue for a simple causeand-effect story of how self-efficacy and NOS are coupled. Rather, we aim to (i) illustrate that they are coupled and (ii) begin charting the space of potential mechanisms by which the coupling occurs. In the remainder of this section, we discuss implications for research (including limitations of this study) and implications for design and implementation of research experiences for undergraduates.

\section{A. Implications for research}

\section{The need for more narrative qualitative research on undergraduate research experiences}

Previous work on undergraduate research experiences, even when relying on interviews rather than surveys, generally ends up coding and categorizing responses instead of telling stories about individual students' experiences [8]. This study demonstrates the value of rich descriptions of students' self-efficacy and NOS views in undergraduate research experiences. Prior quantitative work targeting the outcomes of undergraduate research experiences has been valuable in demonstrating that undergraduate research experiences lead to several positive outcomes, including shifts in self-efficacy and in NOS views [4-12]. The field would now benefit from finergrained qualitative and quantitative explorations of how the positive outcomes come about and the contextual factors that make a difference. Developing a qualitative "feel" for these shifts in self-efficacy and NOS views is especially important when studying contexts such as the Physics 299B research seminar, where the research projects are variegated and sometimes nebulous, creating a wide space of possible outcomes. This paper makes an initial contribution to understanding what these shifts look like, and how they might be connected, in individual cases.

Future research will explore how the details and stability of shifts in students' self-efficacy and NOS views depend on the many research contexts in which students engage. The term "research experience" encompasses many kinds of activities, and we expect that different kinds of projects lead to different learning trajectories. For example, Frederick's research project was broad and exploratory, whereas Wyatt's had a clear outline. This plausibly contributed to Frederick's sense that researchers have "no idea what they're doing" and Wyatt's sense of hierarchy, with those at the top of the chain determining the direction of the research. Savannah's research project also began with a significant amount of background reading, which likely influenced how she framed her activity. Different kinds of interactions with research mentors could position students differently with respect to experts and the physics community.

Future work will also identify influential aspects of the classroom context. The 299B class was mainly comprised of class discussions, which likely influenced students' interpretation and reinterpretation of their experiences and influenced their willingness to share during class (and interviews). More work is needed to see whether a similar connection between self-efficacy and NOS views exists in research programs with different goals or different support structures.

We acknowledge that there are limitations to our work so far. Students' shifts in views were reconstructed as students described them in interviews. We took students' narratives at face value. We would need more data, such as preinterviews, to triangulate students' reflections with their initial views, and to uncover additional factors that influenced students' experiences. In addition, we acknowledge that NOS views are sensitive to context, including the interview context [40]. More work is needed to understand the stability of these NOS views and self-efficacy in other contexts. And we cannot know from this study how widely we can generalize the connection between shifts in selfefficacy and shifts in NOS views. This study is an existence proof of the connection, and an initial foray into some of the nuances, which invites further research to explore both generalizability and contextual influences.

\section{Problematizing measurements of self-efficacy in science education}

In this section we discuss an implication for research that goes beyond studies of undergraduate research experiences. Self-efficacy, as conceptualized by Bandura and others, is a person's views about oneself, specifically, views about one's ability to succeed at a given endeavor. By this conceptualization, a shift in self-efficacy represents a shift in one's views about one's ability. For Wyatt and Frederick, however, shifts in self-efficacy stemmed in part from shifts in their views about the nature of the endeavor, not just shifts in views about their abilities. For example, Wyatt's gain in self-efficacy for cosmology research stemmed in part from coming to see that advanced mathematics is not required, rather than from coming to see himself as good at advanced mathematics. Frederick's gain in self-efficacy stemmed not from coming to see himself as knowing what 
he was doing, but rather from seeing that researchers who do not know what they are doing can make progress. In other words, shifts in these students' self-efficacy for research were not merely coupled to shifts in views about the nature of science; the shifts in self-efficacy were partly constituted by shifts in views about NOS.

This is important, because previous research has treated self-efficacy and views about NOS (or "personal epistemologies" about the nature of knowledge and knowing) as two separate constructs, the correlations between which can be empirically tested [42-47]. We are arguing that selfefficacy and NOS or epistemology views are overlapping constructs and hence surveys and coding schemes cannot help but to "conflate" them.

For instance, consider this item from the Research Methods section of the URQ:

\section{"Carrying out experiments is something I can do."}

Suppose a student responds to this item before and after a research internship, with a positive shift toward stronger agreement. This shift could occur if the student has a consistent view about what carrying out experiments entails and gains confidence in his ability to do so. Or, this shift could occur if he gains no confidence in his abilities but comes to see carrying out experiments in a way more aligned with his abilities. Or, the shift could reflect a combination of a change in confidence and a change in views about the nature of experimentation. Without further evidence, none of these interpretations should be favored over the others.

To make these considerations more concrete, we can imagine how Wyatt and Frederick would respond to the URQ item, pre- and post-Physics 299B. Frederick would likely shift toward greater agreement, largely because he has come to see "experimentation" as more improvisational and therefore less reliant on having an expertly laid plan. Wyatt might also display a positive shift, but the shift would capture only a fraction of his increased self-efficacy for cosmology research, since much of the increase reflects his realization that cosmology research involves significant experimentation. (The other URQ Research Methods items, listed in Sec. II, share this same problem.) Our point is that positive shifts in the URQ Research Methods subscale indicate neither the nature nor the magnitude of shifts in self-efficacy for research, at least for Wyatt and Frederick.

Similar concerns apply to self-efficacy surveys and coding schemes targeting other components of science learning. For instance, consider this item from SOSESC-P, which probes students' self-efficacy for succeeding in a physics class:

"I don't usually worry about my ability to solve physics problems."

A student could display a positive pre-post shift for multiple reasons. The student could have a consistent view of problem solving as a matter of finding the right equations and plugging in the knowns to find the unknowns, and gain confidence in her ability to do so. Or, the student might hold unwavering views about her high ability to think conceptually and her low ability to carry out mathematical manipulations, while coming to see "problem solving" as more conceptual and less plug-and-chug than she initially thought. The SOSESC-P item above would register the same shift for these two very different outcomes. And the same interpretational ambiguity applies to other SOSESC-P items.

This critique does not call into question the importance of studying and instructionally targeting self-efficacy, which correlates with key outcomes such as motivation and retention [14,15,48]. And up to a point, a researcher can take an increase in self-efficacy (as measured by SOSESC-P or other instruments) as a positive outcome, without needing to drill deeper into interpretation. But in PER-based courses that emphasize conceptual understanding and collaborative active learning, what counts as a "good" outcome quickly becomes more complicated. If students' SOSESC-P scores increase largely because they gain confidence in their ability to plug and chug through equations and they see that ability as central to success in the course, some instructors would count that as a bad result, both for the students' learning and for the rewards structure of the course. By contrast, if a class's SOSESC-P scores decrease slightly because students come to see physics as a nuanced blend of conceptual and symbolic reasoning rather than a straightforward application of equations, that could count as a mixed outcome rather than an unequivocally bad outcome.

In short, the Wyatt and Frederick cases illustrate how self-efficacy can be not only coupled to but partially comprised of views about the nature of science. This coconstitutive nature of the two constructs in the context of science education makes any probe of self-efficacy a conflated probe of one's confidence about succeeding at an intellectual endeavor and their views about the nature of that endeavor. As a result, researchers must consider multiple interpretations of a given shift in self-efficacy, at both the individual and the classroom level.

\section{B. Implications for programming and instruction}

In the larger study from which we extracted the three case studies in this paper, many students (including Wyatt and Frederick) described initial feelings of intimidation. We emphasize the importance of lowering barriers to participation and supporting students as they begin research. In particular, many students described feeling like first-year students do not know enough, and some thought they were not sufficiently talented relative to their peers. Our research suggests that helping students shift their views about the nature of science could lower the barrier. Specifically, helping students see that scientific knowledge generation is 
distributed among many people, with novices in the mix, can potentially ameliorate feelings of intimidation and help students feel like they are ready to contribute to research.

Of course, the first step is getting students to try research in the first place. Some 299B students said they would not have pursued research without this course. Like a third of 299B students, Wyatt and Frederick continued to work with their 299B research mentors through summer, which we take as a marker of success. So, the support provided by a seminar such as 299B can help disrupt the typical pattern by which students self-select into research and find research opportunities by word of mouth-a process that disproportionately leaves out less confident and "networked" students, and thereby risks losing students who have the potential to become great researchers.

\section{ACKNOWLEDGMENTS}

We would like to thank Angela Little, Stephen Secules, Ayush Gupta, and Dimitri Dounas-Frazier and members of the UMD Physics Education Research Group for their feedback, as well as thoughtful anonymous reviewers. This work is supported by NSF DUE- 1245590 and the UMD Physics Department Office of Student and Educational Services.
[1] P. W. Irving and E. C. Sayre, Conditions for building a community of practice in an advanced physics laboratory, Phys. Rev. ST Phys. Educ. Res. 10, 010109 (2014).

[2] S. Olson and D. G. Riordan, Engage to Excel: Producing One Million Additional College Graduates with Degrees, in Science, Technology, Engineering, and Mathematics. Report to the President (Executive Office of the President, Washington, DC, 2012).

[3] Business-Higher Education Forum (BHEF), The U.S. STEM Undergraduate Model: Applying System Dynamics to Help Meet President Obamas Goals for One Million STEM Graduates and the U.S. Navys Civilian STEM Workforce Needs, Tech. Rep. (2013).

[4] E. Seymour, A.-B. Hunter, S. L. Laursen, and T. DeAntoni, Establishing the benefits of research experiences for undergraduates in the sciences: First findings from a three-year study, Sci. Educ. 88, 493 (2004).

[5] R. Taraban and E. Logue, Academic factors that affect undergraduate research experiences J. Educ. Psychol. 104, 499 (2012).

[6] D. Lopatto, Survey of Undergraduate Research Experiences (SURE): First findings, Cell Biol. Educ. 3, 270 (2004).

[7] R. E. Landrum and L. R. Nelsen, The undergraduate research assistantship: An analysis of the benefits, Teach. Psychol. 29, 15 (2002).

[8] A.-B. Hunter, S. L. Laursen, and E. Seymour, Becoming a scientist: The role of undergraduate research in students' cognitive, personal, and professional development, Sci. Educ. 91, 36 (2007).

[9] S. Laursen, A.-B. Hunter, E. Seymour, H. Thiry, and G. Melton, Undergraduate Research in the Sciences: Engaging Students in Real Science (John Wiley \& Sons, New York, 2010).

[10] R. Taraban and R. L. Blanton, Creating Effective Undergraduate Research Programs In Science: The Transformation from Student to Scientist (Teachers College Press, New York, NY, 2008).
[11] S. E. Branch, A. Woodcock, and W. G. Graziano, Person orientation and encouragement: Predicting interest in engineering research, J. Eng. Educ. 104, 119 (2015).

[12] D. Lopatto and S. Tobias, Science in Solution: The Impact of Undergraduate Research on Student Learning (Research Corporation for Science Advancement, Tucson, AZ 2009), 1st ed.

[13] V. Sawtelle, E. Brewe, and L. H. Kramer, Exploring the relationship between self-efficacy and retention in introductory physics, J. Res. Sci. Teach. 49, 1096 (2012).

[14] M. Bong, Role of self-efficacy and task-value in predicting college students' course performance and future enrollment intentions, Contemp. Educ. Psychol. 26, 553 (2001).

[15] K. D. Multon, S. D. Brown, and R. W. Lent, Relation of self-efficacy beliefs to academic outcomes: A metaanalytic investigation., J. Counsel. Psychol. 38, 30 (1991).

[16] A. Bandura, Self-Efficacy: The Exercise of Control (Freeman, New York, 1997).

[17] S. L. Britner and F. Pajares, Sources of science self-efficacy beliefs of middle school students, J. Res. Sci. Teach. 43, 485 (2006).

[18] H. Fencl and K. Scheel, Engaging students: And examination of the effects of teaching strategies on self-efficacy and course climate in a nonmajors physics course, J. Coll. Sci. Teach. 35, 20 (2005).

[19] V. Sawtelle, Ph.D. thesis, Florida International University, 2011.

[20] N. G. Lederman, Students' and teachers' conceptions of the nature of science: A review of the research, J. Res. Sci. Teach. 29, 331 (1992).

[21] N. G. Lederman, F. Abd-El-Khalick, R. L. Bell, and R. S. Schwartz, Views of nature of science questionnaire: Toward valid and meaningful assessment of learners' conceptions of nature of science, J. Res. Sci. Teach. 39, 497 (2002).

[22] A. Elby, C. Macrander, and D. Hammer, Epistemic cognition in science, Handbook Epistemic Cognition (Routledge, New York, NY, 2016). 
[23] K. Dunbar, How scientists really reason: Scientific reasoning in real-world laboratories, Nature of Insight (The MIT Press, Cambridge, MA, 1995).

[24] K. K. Cetina, Laboratory studies: The cultural approach to the study of science, Handbook of Science and Technology Studies (Los Angeles, CA, 1995).

[25] B. Latour, Science in Action: How to Follow Scientists and Engineers through Society (Harvard University Press, Cambridge, MA, 1987).

[26] G. J. Kelly and J. Green, The social nature of knowing: Toward a sociocultural perspective on conceptual change and knowledge construction, Perspectives on Conceptual Change: Multiple Ways to Understand Knowing and Learning in a Complex World (Routledge, Mahwah, NJ, 1998).

[27] D. Papineau, Philosophy of Science (Wiley Online Library, 1996).

[28] B. Latour and S. Woolgar, Laboratory Life: The Construction of Scientific Facts (Princeton University Press, Princeton, NJ, 2013).

[29] S. Shapin, Here and everywhere: Sociology of scientific knowledge, Annu. Rev. Sociol. 21, 289 (1995).

[30] M. Zenzen and S. Restivo, The mysterious morphology of immiscible liquids: A study of scientific practice, Social science information / International Social Science Council 21, 447 (1982).

[31] H. R. Bernard, Social Research Methods: Qualitative and Quantitative Approaches (Sage, Newbury Park, CA, 2012).

[32] H. Becker and B. Geer, Participant observation and interviewing: A comparison, Human organization : Journal of the Society for Applied Anthropology 16, 28 (1957).

[33] B. Jordan and A. Henderson, Interaction analysis: Foundations and practice, J. Learn. Sci. 4, 39 (1995).

[34] A. H. Schoenfeld, Reflections of an accidental theorist, J. Res. Math. Educ. 41, 104 (2010).

[35] R. A. Engle and F. R. Conant, Guiding principles for fostering productive disciplinary engagement: Explaining an emergent argument in a community of learners classroom, Cognit. Instr. 20, 399 (2002).

[36] R. A. Engle, F. Erickson, R. Goldman, R. Hall, T. Koschmann, J. L. Lemke, M. G. Sherin, and B. L. Sherin, Conducting video research in the learning sciences: Guidance on selection, analysis, technology, and ethics, J. Learn. Sci. 19, 3 (2010).

[37] M. Eisenhart, Generalization from qualitative inquiry, Generalizing from Educational Research: Beyond Qualitative and Quantitative Polarization (Routledge, New York, NY 2009).
[38] Much of the interview-based NOS research applies a predetermined analytical framework to participants' responses to specific questions about the nature of science [21]. Our approach, finding emergent themes in students' reflections on their experiences, more closely resembles Hammer's [39] approach to studying aspects of students' epistemologies of physics as they emerged in a broad set of interview prompts.

[39] D. Hammer, Epistemological beliefs in introductory physics, Cognit. Instr. 12, 151 (1994).

[40] D. Hammer and A. Elby, On the form of a personal epistemology, in Personal Epistemology: The Psychology of Beliefs about Knowledge and Knowing (Mahwah, NJ, 2002), pp. 169-190.

[41] R. Stevens, K. O'Connor, L. Garrison, A. Jocuns, and D. M. Amos, Becoming an engineer: Toward a three dimensional view of engineering learning, J. Eng. Educ. 97, 355 (2008).

[42] E. Peters and A. Kitsantas, The effect of nature of science metacognitive prompts on science students content and nature of science knowledge, metacognition, and self-regulatory efficacy, School Sci. Math. 110, 382 (2010).

[43] O. Yilmaz-Tuzun and M. S. Topcu, Relationships among preservice science teachers epistemological beliefs, epistemological world views, and self-efficacy beliefs, Int. J. Sci. Educ. 30, 65 (2008).

[44] V. L. Akerson and L. A. Donnelly, Relationships among learner characteristics and preservice elementary teachers views of nature of science, J. Elem. Sci. Educ. 20, 45 (2008).

[45] S. A. Southerland, A. Johnston, and S. Sowell, Describing teachers' conceptual ecologies for the nature of science, Sci. Educ. 90, 874 (2006).

[46] A. M. L. Cavallo, W. H. Potter, and M. Rozman, Gender differences in learning constructs, shifts in learning constructs, and their relationship to course achievement in a structured inquiry, yearlong college physics course for life science majors, School Sci. Math. 104, 288 (2004).

[47] J. A. Chen and F. Pajares, Implicit theories of ability of Grade 6 science students: Relation to epistemological beliefs and academic motivation and achievement in science, Contemp. Educ. Psychol. 35, 75 (2010).

[48] K. McLaughlin, M. Moutray, and O. T. Muldoon, The role of personality and self-efficacy in the selection and retention of successful nursing students: a longitudinal study, J. Adv. Nurs. 61, 211 (2008). 